\title{
A FRAGILIDADE DA PREVALÊNCIA DO NEGOCIADO SOBRE O LEGISLADO
}

\author{
Juliana Machado Sorgi ${ }^{1}$ \\ Elve Miguel Cenci ${ }^{2}$
}

RESUMO: O presente artigo aborda, através de pesquisa bibliográfica, a problemática da prevalência do negociado sobre o legislado no Direito do Trabalho. Tem por objetivo apontar a insegurança jurídica que essa prática pode trazer, sem, contudo, alcançar real redução do desemprego e/ou fomento da economia, como se promete. Para tanto, utiliza-se de analises de decisões do STF e do Projeto de Lei da Reforma trabalhista, trazendo como contraponto a realidade da liberdade sindical do Brasil. Conclui ser temerária, da forma como proposta, a prevalência da negociação coletiva, elaborada em espaço de esparsa participação popular, em detrimento da legislação trabalhista, democraticamente conquistada.

Palavras-chave:. Direito do Trabalho. Liberdade. Negociado. Reforma. Sindicatos.

\section{THE FRAGILITY OF THE PREVALENCE OF THE NEGOTIATED OVER THE LEGISLATED}

\begin{abstract}
:
This article approaches, through bibliographical research, the problem of the prevalence of negotiated over legislated. This paper aims to describes the legal uncertainty that this practice can bring, without, however, achieving real reduction of unemployment and/or economic development. In this way, an analysis of decisions of the STF and the Draft Law of Labor Reform will be made, bringing as a counterpoint the reality of freedom of association in Brazil. It concludes that the prevalence of collective bargaining, elaborated in a space of sparse popular participation, in contrast with democratically conquered labor legislation, is reckless, as it is proposed.
\end{abstract}

Key-words: Labor Law. Freedom. Negotiated. Reform. Unions.

\section{INTRODUÇÃO:}

O Direito Individual do Trabalho trata-se de ramo cogente do ordenamento pátrio, uma vez que regido pelo princípio da proteção ao trabalhador, este considerado

\footnotetext{
${ }^{1}$ Mestranda em Direito Negocial na Universidade Estadual de Londrina (UEL), 2016/2018. Especialista em Direito do Trabalho e Processo do Trabalho pela Faculdade Arthur Thomas (FAAT), 2017. Especialista em Direito Civil e Processo Civil pela Universidade Estadual de Londrina (UEL), 2013. Graduada em Direito pela Universidade Estadual de Londrina (UEL), 2010.

${ }^{2}$ Possui graduação em filosofia pela universidade de Passo Fundo - UPF/RS, graduação em direito pela FML/PR, mestrado em filosofia pela Pontifícia Universidade Católica do Rio Grande do Sul - PUCRS/RS e doutorado em filosofia pela Universidade Federal do Rio de Janeiro - UFRJ/RJ.
} 
hipossuficiente na relação de trabalho. Nas relações coletivas de trabalho, a expectativa é que não exista tal desigualdade, devendo as categorias serem representadas pelos seus Sindicatos.

Espera-se, ainda, que os Sindicatos sejam compostos de membros democraticamente eleitos por seus representados e associados, de modo a melhor defender os interesses destes. A proposta é, assim, da criação de um espaço de debate propício à negociação das categorias e ao alcance de melhorias mediante concessões recíprocas.

Todavia, percebe-se que, a exemplo de diversos outros espaços de debate na pósmodernidade, as discussões nos Sindicatos encontram-se esvaziadas da participação popular, sendo, muitas vezes, monopolizadas pelos interesses individuais, em geral de um pequeno grupo que ascende aos cargos diretivos.

E é justamente neste contexto que a proposta de prevalência do negociado sobre o legislado, que já tem sido adotada em recentes decisões emanadas do STF e que é destaque do texto do Projeto de Lei da Reforma Trabalhista (PL n 6.787/2016), toma lugar e merece atenção e análise.

A problemática, então, reside na fragilidade da prevalência do negociado sobre o legislado diante do tipo de liberdade de que efetivamente se constituem as negociações coletivas - nas quais, como será desenvolvido, não predomina o debate em prol de melhorias coletivas, mas sim de uma liberdade negativa - e dos efeitos nocivos advindos da sobreposição de negociações realizadas nesta esfera à legislação pátria.

Assim, para trabalhar está problemática, a pesquisa visa, através de análise bibliográfica, fazer um traçado político cronológico sobre a tendência atual de prevalência do negociado sobre o legislado no Direito, demonstrando como essa vertente está disposta na Projeto de Reforma Trabalhista atual e como, nos moldes que a reforma vem sendo proposta, há uma incongruência entre a liberdade de negociação coletiva que se prega e a realidade sindical atual em que o Brasil está inserido.

\section{O NEGOCIADO SOBRE O LEGISLADO.}

No contexto político e judicial atual em que propostas de reforma trabalhista ganham lugar, a discussão a respeito da prevalência do negociado sobre o legislado tem merecido atenção. 
Em relação à dinâmica entre negociações coletivas e legislação, a CLT, em matéria de Direito Coletivo, já sofreu forte influência da Constituição Federal de 1988, que, a partir de sua instituição, assegurou autonomia para os sindicatos celebrarem negociações coletivas, com reconhecimento estatal de seu teor (art. $7^{\circ}, \mathrm{XXVI}$, da $\mathrm{CF} / 88$ ), mas sem que tais pactuações estejam infensas ao controle jurisdicional.

Ou seja, foi assegurado a negociação coletiva a esfera da ampliação de direitos e a esfera da flexibilização, nos temas em que a Constituição Federal 1988 expressamente autorizou (redução salarial, compensação de jornada de trabalho e elastecimento das jornadas dos turnos ininterruptos de revezamento), consagrando-se o princípio da adequação setorial negociada.

Para Maurício Godinho Delgado (DELGADO, 2016, p. 1465-1466), seria esse princípio o grande balizador das negociações coletivas em nosso modelo constitucional atual, assegurando-se que a prevalência do acordado sobre o legislado ocorresse em apenas duas hipóteses: a) quando a negociação coletiva implementar um padrão de direito superior ao padrão geral oriundo da legislação heterônoma aplicável; b) quando as normas negociadas transacionam setorialmente parcelas trabalhistas de indisponibilidade relativa, compreendidas pelo autor como aquelas que não envolvem o patamar civilizatório mínimo de direitos trabalhistas e a dignidade dos trabalhadores (por exemplo, salário mínimo, formalização do vínculo de emprego, normas de saúde e segurança, etc.). A negociação, ainda a partir da matriz constitucional, seria espaço para transação, mediante concessões recíprocas, mas jamais para renúncia.

A Justiça do Trabalho, salvo exceções, vem mantendo a limitação material da negociação coletiva ao princípio da adequação setorial negociada e assim mantendo, sempre que possível, as parcelas de norma pública que são consideradas de indisponibilidade absoluta,

pelo fato de constituírem patamar civilizatório mínimo nas relações de trabalho. Esses direitos não podem ser suprimidos ou sequer reduzidos, mesmo mediante negociação coletiva, sob pena de afrontar a dignidade da pessoa humana e a valorização do trabalho, que são, segundo dispõe o artigo $1^{\circ}$, III e 170 da Constituição Federal, fundamentos da República Federativa do Brasil.

Seguindo essa linha, o Tribunal Superior do Trabalho consolidou este entendimento em suas súmulas e julgados. A título de exemplo, cita-se a súmula 437, II, do TST que dispõe: 
"É inválida cláusula de acordo ou convenção coletiva de trabalho contemplando a supressão ou redução do intervalo intrajornada porque este constitui medida de higiene, saúde e segurança do trabalho, garantido por norma de ordem pública (art. 71 da CLT e art. $7^{\circ}$, XXII, da CF/1988), infenso à negociação coletiva"

Entretanto, desde 2015 vem ganhando força nos noticiários e demais mídias a intenção do Governo Federal e do Congresso Nacional de alterar a legislação trabalhista, de forma a passar a permitir a prevalência do acordado/negociado sobre o legislado. Aproveitando o momento político brasileiro, o Supremo Tribunal Federal colocou em pauta diversos julgamentos atinentes a matérias trabalhistas dentre as quais está o reconhecimento dos acordos coletivos de trabalho e das convenções coletivas de trabalho (art. $7^{\circ}, \mathrm{XXVI}$, da CRFB/88). Com isso, a discussão a respeito da (i)limitação material da negociação coletiva foi reaberta para discussão também no âmbito jurisprudencial.

Foi em meio a esse cenário que em 08 de setembro de 2016, nos autos do Recurso Especial 895.759/PE, o Ministro Teori Zavascki proferiu decisão monocrática (DJE de 13.09.2016), reformando decisão ${ }^{3}$ do TST que já havia manifestado entendimento diverso e firmando o entendimento segundo o qual é válida a cláusula de norma coletiva que promova a supressão das horas in itinere, desde que compensada pela concessão de outras vantagens ao trabalhador.

Nesse caso, o TST já havia considerado ilegal (com base no artigo $58, \S 1^{\circ}$ da CLT) a supressão das chamadas horas in itinere, mas, invocando precedente de $2015^{4}$, o Ministro

\footnotetext{
${ }^{3}$ AGRAVO EM EMBARGOS DE DECLARAÇÃO EM RECURSO DE REVISTA. INTERPOSIÇÃO NA VIGÊNCIA DA LEI No 13.015/2014. HORAS IN ITINERE. CLÁUSULA NORMATIVA QUE SUPRIME O DIREITO À REMUNERAÇÃO. INVALIDADE. MATÉRIA PACIFICADA NESTA CORTE. INCIDÊNCIA DO ARTIGO 894, § $2^{\circ}$, DA CLT. CONTRARIEDADE NÃO CARACTERIZADA À SÚMULA No 90 DO TST. Nos termos do artigo 894, $\S 2^{\circ}$, da CLT, com a redação dada pela Lei ${ }^{\circ}{ }^{\circ} 13.015 / 2014$, a divergência apta a ensejar os embargos deve ser atual, não se considerando tal a ultrapassada por súmula do Tribunal Superior do Trabalho ou do Supremo Tribunal Federal, ou superada por iterativa e notória jurisprudência do Tribunal Superior do Trabalho. Discute-se a validade da norma coletiva que suprime o direito ao pagamento das horas in itinere. Por ser direito assegurado pela lei ao trabalhador, o pagamento de horas in itinere não pode ser suprimido por norma coletiva. Inválida é a cláusula convencional que assim dispõe. Tal matéria se encontra pacificada no âmbito desta Corte. [...] (TST, Ag-E-ED-RR- 3554-90.2011.5.12.0003, Relator Ministro: Cláudio Mascarenhas Brandão, Data de Julgamento: 17/12/2015, Subseção I Especializada em Dissídios Individuais, Data de Publicação: DEJT 29/01/2016).

4 O precedente adotado foi o do julgamento do RE 590.415, conhecido como "Caso BESC". Nesse caso, o Banco do Estado de Santa Catarina, antes de ser privatizado, firmou um acordo coletivo com o sindicato dos empregados em que constava uma cláusula de quitação geral. Ou seja, pela negociação o empregado que aderisse ao plano recebia indenização e estaria impedido de obter qualquer diferença em processo judicial
} 
Teori Zavascki decidiu aplicá-lo sob o fundamento de que houve registro, na decisão, de que a supressão da parcela foi compensada com outros itens específicos de vantagens compensatórias concedidas.

Observa-se, desse modo, que a tese da prevalência do negociado sobre o legislado já começa a ser sedimentada na jurisprudência do STF, que julgou pela prevalência do pactuado em instrumento coletivo de trabalho sobre a norma heterônoma estatal. A decisão pode ser considerada mais um ponto fora da curva, pois além de tratar-se de decisão monocrática sobre matéria que, a princípio, não guarda semelhança com o precedente de repercussão geral utilizado, ainda concordou com a supressão de um direito previsto em lei.

Uma semana depois da decisão do Ministro Teori Zavascki, o tema estava, novamente, em pauta do TST, que, embora estivesse com forte pressão para que recuasse de suas posições e passasse a aceitar o negociado sobre o legislado, por ampla maioria cumpriu seu papel de proteção ao Direito do Trabalho ao sinalizar que a supressão da verba "atenta" contra os preceitos constitucionais de garantia às condições mínimas de proteção ao trabalho.

De todo modo, a concessão de vantagens compensatórias especificadas parece converter-se na chave da questão quando se trata de inserir cláusulas restritivas ou supressivas de Direitos pela via da negociação coletiva. Contudo, o precedente, ainda assim, é extremamente temerário para as garantias e os direitos dos trabalhadores, que já percorreram tantas lutas através da história para galgar seus valores, princípio, regras e direitos garantidos.

O momento é muito oportuno para o debate que aqui se propõe, já que a agenda política e o cenário de crise econômica favorecem a introdução de mecanismos como o defendido pelo STF como ferramenta para, supostamente, alavancar o país, as empresas e consequentemente gerar empregos. Ocorre que, na realidade, a introdução de tais instrumentos tende a acarretar justamente o contrário do que se propõe. Vislumbra-se sério risco às garantias fundamentais que os trabalhadores tiveram asseguradas por décadas. Pode significar até mesmo a destruição da CLT.

trabalhista. Apesar de o TST ter considerado a negociação nula, o STF, em 2015, entendeu pela validade da negociação e conferiu especial relevância ao princípio da autonomia da vontade no âmbito do direito coletivo do trabalho. Assim, a decisão que o trabalho aqui apresentado discute, o RE895.759/PE, foi embasada no julgamento já proferido pelo Supremo Tribunal Federal no "Caso BESC". A decisão monocrática do Ministro Teori Zavascki, baseada em precedente da Corte, foi "possível” por conferir repercussão geral ao tema em face do que prescreve o art. 543-A, § 30, do CPC/1973: "Haverá repercussão geral sempre que o recurso impugnar decisão contrária a súmula ou jurisprudência dominante do Tribunal". 
Nota-se que essa discussão acerca da valorização da negociação coletiva vem sendo indevidamente apropriada por setores que, apesar de estarem aproveitando o momento favorável às reformas do atual governo que preconizam a flexibilização e a desregulação, querem, ao contrário, fragilizar os direitos trabalhistas conquistados a duras penas ao longo da história. Segundo Streek,

Até o momento, as noções de justiça social alheias à lógica do mercado têm resistido às tentativas de racionalização econômica, por mais impositivas que elas tenham se tornado na idade de chumbo da expansão do neoliberalismo. As pessoas se recusaram obstinadamente a abrir mão da ideia de uma economia moral, sob a qual possuem direitos que têm precedência sobre as repercussões das transações de mercado. De fato, sempre que podem - como recorrentemente podem em democracias efetivas —-, tendem de uma maneira ou de outra a insistir na primazia do social sobre o econômico, na proteção de compromissos e obrigações sociais contra as pressões do mercado por "flexibilidade", na expectativa de que a sociedade satisfaça as aspirações humanas a uma vida fora da ditadura dos "sinais" instáveis dos mercados. Provavelmente, é esse o fenômeno que Polanyi descreveu em A grande transformação como um "contra movimento" em reação à transformação do trabalho em mercadoria. (STREECK, 2013, p. 38 )

No programa "uma ponte para o futuro" ${ }^{5}$, apresentado pelo Governo Temer, a principal referência à questão trabalhista apareceu na forma da prevalência dos acordos e convenções coletivas sobre a lei e culminou no Projeto de Lei $n^{\circ} 6.787 / 2016^{6}$, que já passou pela Câmara dos Deputados em 26 de abril de 2017 e aguarda votação no Senado Federal.

Apesar de o fantasma da reforma estar sendo bastante temido e debatido, o tema não é novo. Na década de 1990, ainda no Governo de Fernando Henrique Cardoso, já havia proposta de lei (PL5483/01) ${ }^{7}$ para alterar o artigo 618 da CLT, objetivando dar prevalência

\footnotetext{
5 Programa lançado pelo PMDB, partido de Temer, em outubro de 2015, com o intuito de auxiliar o país a superar a crise econômica. (Programa disponível na íntegra em: http://pmdb.org.br/wpcontent/uploads/2015/10/RELEASE-TEMER_A4-28.10.15-Online.pdf)

${ }^{6}$ Segundo Ementa, projeto "altera a Consolidação das Leis do Trabalho (CLT), aprovada pelo Decreto-Lei ${ }^{\circ}$ 5.452, de $1^{\circ}$ de maio de 1943, e as Leis $\mathrm{n}^{\circ} \mathrm{s} 6.019$, de 3 de janeiro de 1974, 8.036, de 11 de maio de 1990, e 8.212, de 24 de julho de 1991, a fim de adequar a legislação às novas relações de trabalho"

${ }^{7}$ A Ementa do Projeto de Lei é a alteração do artigo 618 da Consolidação das Leis do Trabalho - CLT, estabelecendo que as condições de trabalho ajustadas mediante convenção ou acordo coletivo prevalecem sobre o disposto em lei, desde que não contrariem a Constituição Federal e as normas de segurança e saúde do
} 
ao acordado em detrimento do legislado. Nos anos seguintes vários outros projetos de lei, com conteúdo idêntico, foram apresentados, sem, contudo, encontrarem ambiente favorável para aprovação. Um exemplo ilustrativo ocorreu quando foi discutido o projeto do PPE

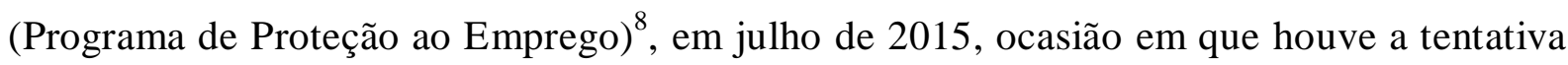
de inclusão de emenda parlamentar acrescentando artigo nessa linha, porém sem êxito. Mais recentemente, em dezembro de 2016, foi proposto o Projeto de Lei $n^{\circ}$ 6.787/2016, chamado de Projeto da Reforma Trabalhista, que traz em seu bojo diversas mudanças no Direito Material e Processual do Trabalho, dentre elas, como parte mais frágil e temerária do projeto, a tentativa de tornar o negociado coletivamente prevalente sobre o legislado mediante acordos e convenções coletivas.

\section{A FRAGILIDADE DO PROPOSTO PELA REFORMA TRABALHISTA}

Como é possível extrair da discussão até aqui desenvolvida, há uma vontade latente em aprovar a Reforma Trabalhista por determinados segmentos da sociedade Enquanto permanecia estagnada no Congresso Nacional, era o Supremo Tribunal Federal (STF) que, de certa forma, vinha assumindo um legítimo protagonismo nessa seara. Contudo, diante da aprovação do Projeto de Reforma trabalhista já na primeira casa, percebe-se que o momento aguardado para legitimar tal ato parece ter chegado ${ }^{9}$.

A atual pauta de reformas é reflexo de uma significativa troca de agenda que está em curso ao longo dos últimos anos, sobretudo a partir da passagem do século XX para o XXI. Justamente em um momento em que os valores democráticos alcançaram prestígio inédito na

trabalho. Contudo, em 08/05/03 o presidente Lula solicitou a retirada do projeto, que foi arquivado somente 11 meses depois, em junho de 2004.

${ }^{8}$ O Programa de Proteção ao Emprego (PPE) foi regulado pela Medida Provisória 680/2015 e alterado pela Medida Provisória (MP) 761/2016, que modificou e prorrogou por mais dois anos (até dezembro de 2018) a vigência do Programa de Proteção ao Emprego (PPE), denominado, agora, de Programa Seguro-Emprego (PSE). Esse programa é uma tentativa do Poder Executivo de ajudar empresas, que devido à crise necessitam diminuir a produção, diminuindo turnos e outros gastos. $\mathrm{Na}$ verdade, trata-se de medida que visa diminuir os gastos do Governo com seguro desemprego, pois os gastos com o programa são tecnicamente menores que os gastos com pagamento de seguro desemprego.

9. Por ser impopular e tirar votos, os setores favoráveis às medidas votadas até o momento entendem que somente um governo sem futuro político e que não planeja a reeleição pode enfrentar os protestos dos segmentos contrários. O Governo Temer investiu agressivamente na publicidade para convencer a sociedade que as reformas propostas até o momento são necessárias e urgentes. Valendo-se do capital político arregimentado com o impeachment e do apoio de segmentos importantes da sociedade, a exemplo do empresariado, mídia e o setor financeiro, teria chegado a hora de enfrentar sindicalistas e oposição em favor das reformas de cunho neoliberal. 
história, as condições de sua efetivação paradoxalmente parecem se exaurir mediante o poder existente (FARIA, 2011, p.38). Essa mudança representou a transição para uma economia global de acirrada concorrência, desterritorializada e com crescente fluxo internacional de bens e serviços que privilegia interconexão financeira, estabilização monetária, auto composição de interesse, auto regularização, flexibilização de direitos e expansão do setor público não estatal. Em contrapartida, nota-se um empobrecimento do lado social, com esvaziamento do modelo social democrata já conquistado. (FARIA, 2011, p.15).

O cenário atual é de preocupação com os direitos sociais futuros, especialmente aqueles organizados em torno do eixo capital/trabalho. Essa preocupação surge não só pela possibilidade real de regressão nos direitos já conquistado, embora essa razão já fosse suficientemente forte para disparar o sinal de alerta, mas também pelo fato de que as principais funções do Direito do Trabalho consistem, em síntese, na "melhoria das condições de pactuação da força de trabalho na vida econômica-social, no caráter modernizante progressista, do ponto de vista econômico e social, desse ramo jurídico.” (DELGADO, 2015, 115)

Essas funções do Direito do Trabalho são comprovadas e afirmadas na própria experiência capitalista dos países desenvolvidos, locais em que a afirmação do valortrabalho $^{10}$ despontou como um dos mais notáveis marcos de estruturação da democracia social no mundo contemporâneo (DELGADO, 2015, 114). Ainda, segundo o autor (DELGADO, 2015 , 116):

É pela norma jurídica trabalhista, interventora no contrato de emprego, que a sociedade capitalista, estruturalmente desigual, consegue realizar certo padrão genérico de justiça social, distribuindo a um número significativo de indivíduos (os empregados devidamente registrados), em alguma medida, ganhos do sistema econômico. À medida que o contrato empregatício desponta como o principal veículo de conexão do indivíduo com a economia, seu ramo jurídico regulador - o Direito do Trabalho - torna-se um dos mais eficientes e genéricos mecanismos de realização de justiça social no sistema capitalista

\footnotetext{
${ }^{10}$ Em seu livro Capitalismo, Trabalho e Emprego, Maurício Godinho Delgado desenvolve todo um histórico político econômico comparativo dos países desenvolvidos com o Brasil e demonstra que "o elevado nível dos salários e do próprio custo total do trabalho não se constitui em obstáculo ao desenvolvimento de tais países (países desenvolvidos) - ao contrário do que se propaga certo tipo de discurso hoje dominante. Ao invés, a densidade e o vigor dessas economias e sociedades muito devem à consistente retribuição que tendem a deferir o valor-trabalho dentro de suas fronteiras. " (DELGADO, 2015, 118)
} 
Contudo, na situação atual, vê-se prosperar discursos de flexibilidade das relações de trabalho como forma de combate ao desemprego. A história dos países desenvolvidos atesta que o resultado da flexibilização é o inverso da promessa feita atualmente no Brasil. O desemprego e a crise atual guardam relação com o eixo capital-trabalho, entretanto, "o segredo acerca da impressionante exclusão social neste País reside no fato de o desenvolvimento capitalista aqui, ao longo do século XX, ter se realizado sem a compatível generalização do Direito do Trabalho na economia e sociedade brasileiras" (DELGADO, 2015, p 122). Essa omissão impediu que a distribuição de renda consequente do Direito do Trabalho fosse alcançada.

Segundo Ricardo Antunes (2006, p.55), observa-se no momento atual um retorno à precariedade do trabalho somente vista anteriormente na época da $1^{a}$ Revolução Industrial. Essas relações atuais de trabalho que violam a dignidade humana não pertencem a uma fase historicamente superada do capitalismo nem constituem um fenômeno paralelo casual dessa formação social. (MAHNKOPF, 2005, p. 61).

Para combater a crise em curso e proteger o trabalho do futuro, as sociedades capitalistas avançadas devem buscar um novo regime de trabalho, com uma nova distribuição do tempo entre as atividades com fins sociais e econômicos. (STREECK, 2014). Entretanto, a reestruturação não pode ser feita seguindo a linha de desprestígio do Direito do Trabalho, como vem sendo feito desde a década de 1990, experimentando resultados negativos. Desde então, cada vez mais, tem sido fomentado o discurso de desregulamentação e flexibilização jurídico-trabalhista. Toda a carga negativa resultante das crises do próprio capitalismo tem sido transferida para o Direito do trabalho.

É oportuno trazer o raciocínio do desembargador Jorge Luis Souto Maior (2017), quando à falácia da existência de uma legislação trabalhista desatualizada:

dos 921 artigos da CLT de 1943, apenas 188 continuam vigentes até hoje e praticamente nenhum destes fixa, digamos assim, custos aos empregadores. Do ponto de vista legislativo, o que rege as relações de trabalho no Brasil, em consonância com a Constituição, é uma série de leis esparsas, editadas em grande número do ano de 1964 em diante, tendo sido a maioria, inclusive, na direção da dita "flexibilização", tanto que o teor do PL 6787/16, que visa, segundo se diz, "modernizar a legislação do trabalho", alterando mais de 200 dispositivos da CLT, toca apenas em 7 artigos da CLT que estavam vigentes em 1943; e mesmo assim não os revoga por inteiro. 
Sendo verdadeiros ou não os motivos da criação do projeto de Reforma Trabalhista $\mathrm{n}^{\mathrm{o}}$ 6.787/2016, fato é que ele foi criado, apresentado e já votado na primeira casa do Congresso Nacional. E, como explicado pelo Desembargador Souto Maior, trará um destino para sociedade brasileira diverso daquele que lhe foi conferido pela Constituição Federal:

o projeto busca uma reconstrução dos destinos da sociedade brasileira e o faz, em conformidade com os interesses exclusivos do setor econômico (que são legítimos, mas não são os únicos) e isso - para além dos desejos individuais, ou seja, do que cada um possa considerar que seria o melhor para o país - contraria o pacto firmado na Constituinte de 1987, sendo que o pior de tudo são as estratégias políticas que se têm utilizado para chegar a esse resultado, fazendo com que não estejam em risco apenas os direitos dos trabalhadores, mas a democracia e o Estado de Direito nacionais, repercutindo, pois, no cotidiano de todos, independentemente de seus crédulos ou ideologias, mas, claro, mais diretamente, e no sentido negativo, na vida dos trabalhadores." (SOUTO MAIOR, 2017, p.1)

As mudanças propostas para as leis trabalhistas seriam até mínimas se não fosse a disfarçada tentativa de revogar direitos historicamente conquistados e convertidos em preceitos constitucionais. Os artigos 611-A e 611-B do PL 6787/2016 tratam da "flexibilização" por meio de acordo coletivo ou convenção coletiva e, além de trazerem em seu bojo a legalização da prática temerária da prevalência do negociado sobre o legislado, apresentam erros de ordem material que deixam os direitos sociais trabalhistas ainda mais desprovidos de qualquer tipo de segurança jurídica.

O caput do artigo 611-A diz que "A Convenção coletiva do trabalho e o acordo coletivo de trabalho têm prevalência sobre a lei quando, entre outros, dispuserem sobre:" Esse artigo possui 16 (dezesseis) incisos e $5 \S$ com a lista de direitos que, entre outros, poderão ser negociados independentemente do disposto na lei, entre eles estão os referentes à jornada de trabalho, intervalo, banco de hora, adesão no programa de seguro desemprego etc..

Primeiramente é importante ressaltar que Convenções Coletivas e Acordos Coletivos já têm força de lei no ordenamento jurídico trabalhista. Contudo, privilegia-se a aplicação da norma mais benéfica para o trabalhador, seja ela lei, convenção e acordo. Ou seja, diante do caput do artigo 611-A do projeto de lei já se verifica que não será mais aplicada a norma mais benéfica e, sim, aquela que for acordada. 
Ainda no caput do artigo 611-A, nota-se a expressão "entre outras" que faz com que a lista de possibilidade do negociado sobre o legislado seja extremamente abrangente, ou seja, sem qualquer segurança jurídica quanto aos direitos disponíveis em negociação. A insegurança jurídica fica ainda mais evidente na análise do caput do artigo 611-B, ao descrever que "constituem objeto ilícito de convenção coletiva ou de acordo coletivo de trabalho, exclusivamente, a supressão ou a redução dos seguintes direitos (segue lista de direitos nos incisos)". Aqui a palavra "exclusivamente" faz com que o rol de direitos indisponíveis por meio de negociação sejam bem limitados - quando deveria ser o contrário.

O ponto mais frágil do projeto recai sobre a tentativa de tornar o negociado coletivamente predominante sobre o legislado através de acordos e convenções coletivas. Se não bastassem as "falhas" do texto, ainda há o problema estrutural que esbarra no fato de o Brasil não ter ratificado a Convenção 87 da Organização Internacional do Trabalho. A OIT preconiza a liberdade sindical plena, uma vez que o Ordenamento Jurídico Brasileiro prevê a unicidade sindical, isto é, a exigência de um só sindicato representar determinada categoria em determinada base territorial, conforme artigo $8^{\circ}$ da Constituição Federal, que não pode ser modificada através de Lei ordinária.

Segundo a desembargadora Vólia Bonfim Cassar (2017, p.1.), “A fragilidade da proposta está exatamente aí, pois não se pode ter liberdade de negociar coletivamente sem a ampla liberdade sindical, com pluralidade sindical, contribuição sindical facultativa e normas coletivas aplicáveis apenas aos associados”. Da forma que se propõe e no momento em que o Brasil se encontra, é inviável defender a prevalência do negociado sobre o legislado. Há, sim, a necessidade de reestruturação de aspectos da legislação trabalhista vigente, porém com iniciativas políticas direcionadas e precisas para assegurar a segurança da renda, a segurança profissional, a segurança de representação para todas as pessoas e a segurança jurídica.

A defesa da prevalência do negociado sobre o legislado, na forma ascendente que começa pelas decisões do Supremo Tribunal Federal e agora chega ao Congresso, coloca em xeque todo o sistema democrático de representatividade.

\section{A LIBERDADE DE NEGOCIAR COLETIVAMENTE SEM A AMPLA LIBERDADE SINDICAL}


A questão aqui exposta da prevalência do negociado sobre o legislado tem como um de seus fundamentos a exaltação do princípio da autonomia da vontade no âmbito do direito coletivo do trabalho. A autonomia coletiva decorre de uma das mais importantes funções do sindicato e a negociação coletiva é condição do exercício da democracia, uma vez que, juntamente com a lei, as normas coletivas compõem um sistema de direitos e de proteção para os trabalhadores.

Entretanto, ao se falar em autonomia coletiva, não se pode olvidar da outra face da moeda que é a liberdade sindical. A Constituição Federal de 1988, responsável por instituir o atual Estado Democrático de Direito, previu no título destinado aos Direitos fundamentais, no artigo $8^{\circ}$, a liberdade de associação sindical. Contudo, logo no inciso II desse dispositivo, encontra-se a determinação da unicidade sindical, ao passo que o inciso IV estabelece a manutenção da contribuição obrigatória. Ou seja, a liberdade sindical no Brasil, tanto horizontal quanto vertical, não é plena.

Para a Organização Internacional do Trabalho (OIE), conforme estabelecido na Convenção $n^{\circ} 87$, a liberdade sindical pressupõe o direito dos trabalhadores constituírem as associações que acharem convenientes e de se filiarem a essas associações, sem nenhuma distinção ou autorização prévia. O diploma ainda prevê a livre organização das entidades sindicais, devendo as autoridades públicas absterem-se de toda intervenção que objetive limitações. Ou seja, infere-se que, para a OIT, a pluralidade é pressuposto para o conceito de liberdade sindical pleno e o mesmo se pode dizer sobre a vedação à contribuição compulsória. Contudo, o Governo Brasileiro não ratificou a Convenção no 87 da CLT, mantendo um modelo de liberdade diferente do defendido pela OIT.

Esse modelo de liberdade mitigada adotado pelo Estado Brasileiro, que mantém a unicidade sindical, não é adequado para se pensar em avanços nas negociações coletivas da forma com propõe o Governo e defende o Supremo Tribunal Federal. A maioria dos países que possuem essa maior autonomia coletiva sindical em prol de negociações coletivas é desenvolvido e optante da liberdade sindical irrestrita, o que não é o caso do Brasil.

Com relação a essa autonomia sindical, entendendo que os sindicatos não podem ficar submetidos ao dirigismo exercido por forças ou poderes estranhos à sua organização, leciona Mozart Victor Russomano (1995, p. 73): 
No Brasil, no regime tradicional da Consolidação da leis do trabalho, inspirada pela Constituição de 1937 (de natureza totalitária), nunca houve autonomia sindical, no sentido justo e escrito acima exposto. Não só o sindicato ficava jungido ao Ministério do Trabalho - desde o seu reconhecimento até a eventual intervenção - como, inúmeras vezes, foi utilizado como instrumento demagógico-partidário. O fim dessa situação só ocorreu mais de cinquenta anos após a instauração do Estado Novo, com o advento da Constituição Federal de 5 de outubro de 1988. O art. 8a, caput e inciso I, declara que o Estado está proibido de intervir, por qualquer forma, na vida sindical.

A realidade sindical brasileira ainda reflete uma sociedade pouco madura, refém de uma história em que se registram sindicatos muito mais vinculados ao atendimento dos interesses estatais e empresariais do que à persecução dos anseios daqueles que deveriam defender. Os sindicatos brasileiros estão próximos ao conceito de liberdade dos modernos de Benjamin Constant, cujo objetivo é a segurança dos privilégios privados e a independência individual, sem grandes preocupações em torno de uma liberdade política (CONSTANT,1985, p.19). Essa liberdade dos modernos, exposta por Benjamin Constant, reflete muito a sociedade atual e se diferencia da liberdade dos antigos, pois nessa "o indivíduo era quase sempre soberano nas questões públicas e escravo em todos os assuntos privados", pois a liberdade para os antigos consubstanciava o direito de ser, já naquela, entre os modernos, ao contrário, “o indivíduo, independente da vida privada, mesmo nos Estados mais livres, só é soberano em aparência" (CONSTANT,1985, p.11).

O desejo de liberdade dos modernos não se refere à vontade de participar da vida política, como era para os antigos, mas visa a não interferência estatal na sua busca pela felicidade pessoal.

Benjamin Constant (1985, p.19) sintetiza seu pensamento da seguinte forma:

O objetivo dos antigos era a partilha do poder social entre todos os cidadãos de uma mesma pátria. Era isso o que eles denominavam liberdade. O objetivo dos modernos é a segurança dos privilégios privados; e eles chamam liberdade as garantias concedidas pelas instituições a esses privilégios.

Apesar de o objetivo sindical ser reproduzir no interior do Estado representativo moderno a democracia direta dos antigos, há na representatividade sindical a eminência do perigo da liberdade moderna, isto é, de que "absorvidos pelo gozo da independência privada e 
na busca de interesses particulares, renunciemos demasiado facilmente a nosso leito de participar do poder público" (CONSTANT,1985, p.23). Esse conceito de liberdade dos modernos reflete o liberalismo, para o qual a participação do cidadão na administração da política objetivando a promoção do bem comum e de uma ordem justa na busca do melhor regime de liberdade política é abandonado em prol do ganho da liberdade individual (RAMOS, 2007, p. 321). Essa prática, no âmbito sindical, acaba por favorecer interesses individuais ou de minorias privilegiadas em detrimento dos interesses da maioria.

Para esse ganho individualista há certa renúncia à ideia do viver político que vincula a proteção e a realização da liberdade com a ideia da participação ativa na coisa pública pela presença de cidadão virtuoso. (RAMOS, 2007, p. 321). Ou seja, para o liberalismo “a liberdade não implica ações virtuosas da cidadania voltadas para o bem comum, pois a sociedade realiza no conjunto, como consequência da busca dos benefícios individuais dos seus agentes, o interesse coletivo" (RAMOS, 2007, p. 321). Já para o republicanismo, ou segundo a conceituação de Benjamin Constant, a liberdade dos antigos "defende uma concepção forte de cidadania que visa à defesa cívica do bem público, cujo valor ultrapassa a mera soma dos interesses individuais”. (RAMOS, 2007, p. 321)

Apesar de o ideário sindical ser revestido de ideais republicanos, pregando a liberdade dos antigos, o que se percebe na sociedade brasileira atual é que cada vez mais os sindicatos passam a espelhar a liberdade dos modernos, de forma que sua representatividade vem sendo tolhida por posicionamentos neoliberais.

Segundo Ramos (2007, 323), "parece razoável a tese de que um modelo de liberdade mais adequado às sociedades modernas não pode ser constituído em termos de escolha disjuntiva entre liberalismo ou republicanismo", mas diante da mudança jurisprudencial e política que vem sendo instaurada, faz-se necessária uma reavaliação das políticas sindicais que fomente um posicionamento mais claro e efetivo na luta pela democracia e pela representação da maioria.

Longe de renunciar a qualquer dos conceitos de liberdade, é preciso encontrar o justo meio para a sociedade atual, principalmente no âmbito do direito coletivo, ou seja, é preciso saber combinar as espécies de liberdade, conforme segue ensinamento de César Augusto Ramos (2007, p. 323):

Um conceito de liberdade deve ser suficientemente amplo para reunir os aspectos positivos no modelo liberal e republicano e ser compatível 
com as sociedades democráticas modernas marcadas pelo pluralismo de grupos, muitas vezes divergentes e antagônicos, e pela diversidade dos interesses individuais que buscam a proteção dos seus direitos.

Correlacionando com a situação apresentada nessa pesquisa, ao se legitimar que as verbas podem ser transacionadas de forma ao negociado prevalecer sobre o legislado, deposita-se grande carga valorativa sobre as entidades sindicais, que serão as responsáveis por avaliar se a compensação de direitos com outras vantagens é pertinente em cada caso concreto para a mitigação e/ou aniquilação de direitos.

Para que haja uma representatividade efetiva e para que o sindicato possa efetivamente negociar, há que se estabelecer um sistema de proteção e garantias, a chamada legislação de sustento ou suporte à liberdade sindical ${ }^{11}$. Indo além, os trabalhadores devem ter maturidade e discernimento para que façam boas escolhas de representantes. Nessa linha segue o ensinamento de Isaiah Berlin:

Para evitar a desigualdade gritante ou a desgraça generalizada, estou pronto a sacrificar parte da minha liberdade ou toda ela: posso agir desse modo voluntária e livremente; mas é à liberdade que estou renunciando em prol de justiça, igualdade ou amor pelos homens companheiros meus. (BERLIN, 2002, p. 232)

Ou seja, para que a metodologia de flexibilização e transação possa funcionar da forma que vem sendo difundida na mídia, defendida pelo STF e levada a termo via projeto de lei no Congresso Nacional, a sociedade precisa ter maturidade para não se perder na liberdade moderna. O caminho adequado implica buscar um justo meio entre a liberdade dos modernos e a liberdade dos antigos, que priorizava a liberdade política e social. Enquanto a sociedade não revelar a capacidade de abrir mão de parcelas de liberdade em prol da comunidade, as negociações coletivas ficarão extremamente prejudicas e corrompidas. A forma mais segura de defesa dos interesses dos hipossuficientes ainda continua sendo a manutenção das normas sociais protetivas que foram conquistas através dos tempos.

Atribuir aos sindicatos o principal poder regulamentar das relações de trabalho sem antes adequar a estrutura sindical existe aos parâmetros internacionais de proteção e

\footnotetext{
${ }^{11}$ São garantias para sindicalistas e trabalhadores exercerem a necessária pressão sobre o setor patronal de modo a não estar, sempre, na dependência da aceitação de qualquer acordo pelo simples fato de manter os empregados de quem já está empregado.
} 
democracia (Convenções no 87 e 98 da OIT, por exemplo) e principalmente sem observar a necessária fruição do tempo de amadurecimento das relações coletivas, parece traduzir-se numa entrega de toda carga histórica e social da legislação trabalhista para sujeitos coletivos ainda rendidos.

\section{CONCLUSÃO}

$\mathrm{Na}$ atual conjuntura do sindicalismo brasileiro, conforme abordado no decorrer do artigo, conclui-se como temerária a adoção da prevalência das negociações coletivas sobre a legislação trabalhista.

A proposta de Lei que propõe, entre outras coisas, a prevalência do negociado sobre o legislado, assim como as teses jurisprudenciais que tem despontado no STF no mesmo sentido, estão assentadas em premissas de valorização e empoderamento da negociação coletiva que não resistem a uma análise empírica mais sólida.

A mera determinação legal ou jurisprudencial de prevalência do negociado sobre o legislado, sem alteração das estruturas que permeiam os processos de negociações não irá, automaticamente, conduzir ao fortalecimento das negociações coletivas.

Para que a política de prevalência do negociado sobre o legislado possa algum dia ser viável necessita-se de um ambiente sindical enraizado em uma liberdade sindical efetiva, pois não se pode ter liberdade de negociar coletivamente sem se ter ampla liberdade para tanto.

Falar em representatividade efetiva e democracia interna para as instituições sindicais é algo de pouca ressonância e credibilidade quando se está inserido em um sistema onde as liberdades sindicais não são plenamente asseguradas e onde não existe um sistema efetivo de proteção e garantias.

Deste ponto, torna-se palpável a incongruência de se determinar que tais negociações coletivas se sobreponham à legislação trabalhista, anulando décadas de conquistas de direitos em nome de uma liberdade mascarada, de uma liberdade que, longe de resolver os problemas do País, reproduz, ainda, egocentrismos.

\section{REFERÊNCIAS BIBLIOGRÁFICAS}


ANTUNES, Ricardo. Afinal, quem é a classe trabalhadora hoje? Margem Esquerda - Ensaios Marxistas, São Paulo, n. 7, p. 55-61, Boitempo, maio 2006;

BERLIN, Isaiah. Dois conceitos de liberdade. In: Estudos sobre a humanidade: uma antologia de ensaios. Tradução Rosaura Eichenberg. São Paulo: Companhia das Letras, 2002.

CASSAR, Vólia Bomfim. Reforma Trabalhista Comentários ao Substitutivo do Projeto de Lei 6787/16. 2017. Disponível em: < http://genjuridico.com.br/wpcontent/uploads/2017/04/Artigo-sobre-a-Reforma-Trabalhista.pdf>. Acesso em 07 de maio 2017;

CONSTANT, Benjamin. Da liberdade dos antigos comparada à dos modernos. In: MONTEIRO, João Paulo et al. Filosofia Política 2. Porto Alegre: L\&PM Editores (UNICAMP/UFRGS - com apoio do CNPQ), 1985.

DELGADO, Maurício Godinho. Curso de Direito do Trabalho. 15 ed. São Paulo: LTr, 2016; FARIA, José Eduardo. O Estado e o Direito depois da crise. São Paulo: Saraiva, 2011;

MAHNKOPF, Birgit. O futuro do trabalho: globalização da insegurança. In: PETERSON, Nikolai; SOUZA, Draiton Gonzaga (orgs.). Globalização e justiça II. Porto Alegre: Edipucrs, 2005 ;

RAMOS, César Augusto. A concepção republicana de liberdade como não-dominação. In: Crítica: revista de filosofia. Londrina: Universidade Estadual de Londrina. v. 12, n.36, p. 301-336, out. 2007.

RUSSOMANO, Mozart Victor. Princípios Gerais do Direito Sindical. 2 ed. Rio de Janeiro: Forense, 1995.

- O liberalismo político e seus críticos. Crítica: revista de filosofia. Londrina: Universidade Estadual de Londrina. v. 10, n. 32, p. 229-264, out. 2005. 
SOUTO MAIOR, Jorge Luiz. A quem interessa essa "reforma” trabalhista?, 2017. Disponível em: <http://www.jorgesoutomaior.com/blog/a-quem-interessa-essa-reforma-trabalhista>. Acesso em 07 de maio 2017;

STREECK, Wolfgang. Tempo Comprado: A crise do capitalismo democrático. Tradução de Marian Toldy e Teresa Toldy. Coimbra: Actual, 2013; 